\title{
Classical caesarean section- A time honoured surgery
}

\author{
Suniti Rawal, Geeta Gurung, Kesang D. Bista \\ Dept of Obs/Gyn, Tribhuvan University Teaching Hospital, Kathmandu, Nepal
}

\begin{abstract}
Classical caesarean section seldom performed worldwide and even at our hospital was carried out in a 37 years old $G_{3} P_{0+2}$ at $36^{+4}$ weeks with the indications of transverse lie, cervical fibroid, low lying placenta, oligohydramnios with severe IUGR and PIH, complicated with intraoperative post partum hemorrhage (PPH).

Though the classical caesarean section (CCS) is almost a forgotten surgery, its importance may be reminded in situations like this when such an intervention becomes imperative and lower segment caesarean section (LSCS) being lesser advantageous.
\end{abstract}

Key words: classical caesarean section, transverse lie, cervical fibroid, low lying placenta

\section{Introduction}

Caesarean section (CS) is a form of childbirth in which a surgical incision is made both in the mother's abdomen as well as in the uterus to deliver the baby out. The history of CS dates back to thousands of year. In Persian mythology, one of its greatest Persian heroes, Rustum was said to have been delivered by CS on his labouring mother Rudabah. Shakespeare in his famous play, Macbeth has mentioned about the CS. ${ }^{1}$ According to mythology, the first CS was performed by Apollo on his lover Coronis, when he delivered Asklepios. History also states that, Robert II of Scotland in 1316 and Edward IV of England both of them were CS born.

The term CS has been thought to be derived after the great Roman leader Julius Caesar, who allegedly was so delivered, but these myths were possibly incorrect as his mother was said to have lived long, even till Julius Caesar reached adulthood. The meaning of CS from the verb caedo; the phase "a matre caesus" (cut out of his mother) in Roman or Latin verb "caedere" means "to cut". Romans then had passed a law called "lex caesarae" allowing a dying pregnant woman to be cut to save the life of the baby. May be the technicality applied then was similar to the classical caesarean section (CCS) today which involves a midline longitudinal incision in the gravid uterus cutting apart its muscle longitudinally, thus allowing a larger space to deliver out the baby safely as is practiced for the same reason in prematurity. ${ }^{1-3}$

Today because of the undesirable complications associated with CCS, its use is limited. ${ }^{2-6}$ Yet it has been accepted in very few indications like; severe kyphoscoliosis, central placenta previa, pregnancy with carcinoma cervix, huge cervical myoma / low corporeal myoma obstructing the lower uterine segment or severe endometriosis or dense pelvic adhesion after multiple caesareans masking the lower uterine segment. ${ }^{7,8}$ And above all, whenever caesarean hysterectomy is contemplated. It has also been applied in a deceased or dying mother or after such mother is declared dead from hit accidents and run or crush injuries, to bring out an alive baby ${ }^{9}$. Thus it is principally employed for separating baby from mother before the body is cremated or buried.

\section{Case}

With the diagnosis of severe IUGR/PIH with oligohydramnios, transverse lie, cervical fibroid, low lying placenta a $\mathrm{G}_{3} \mathrm{P}_{0+2}$ at $36^{+4}$ weeks who had two consecutive abortions soon after her marriage at 3

Correspondences

Suniti Rawal, $M D$

Lecturer, Dept of Obs/Gyn TU Teaching Hospital

Email: sunudinurawal@yahoo.com 


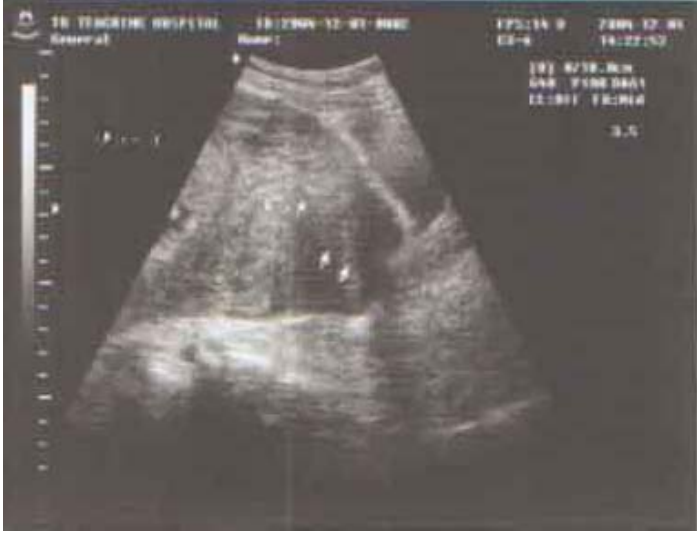

Fig I. Low lying Placenta almost covering the internal

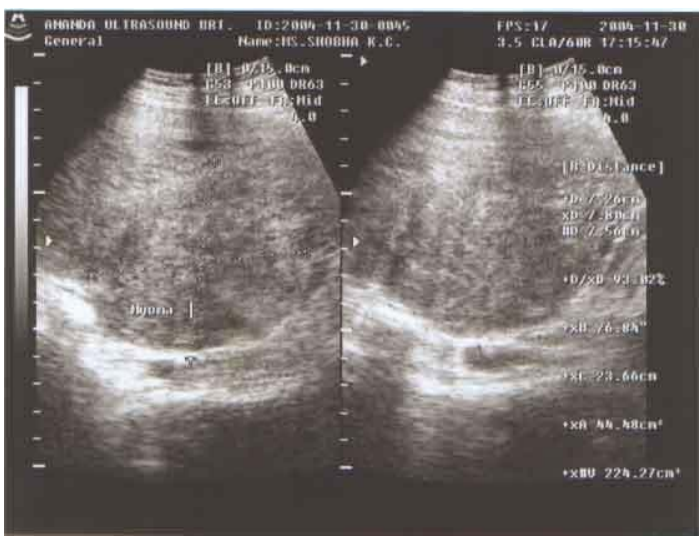

Fig 2. Huge cervical myoma measuring $8.32 \mathrm{cms}$ X $6.67 \mathrm{cms}$ at $36^{+}$weeks

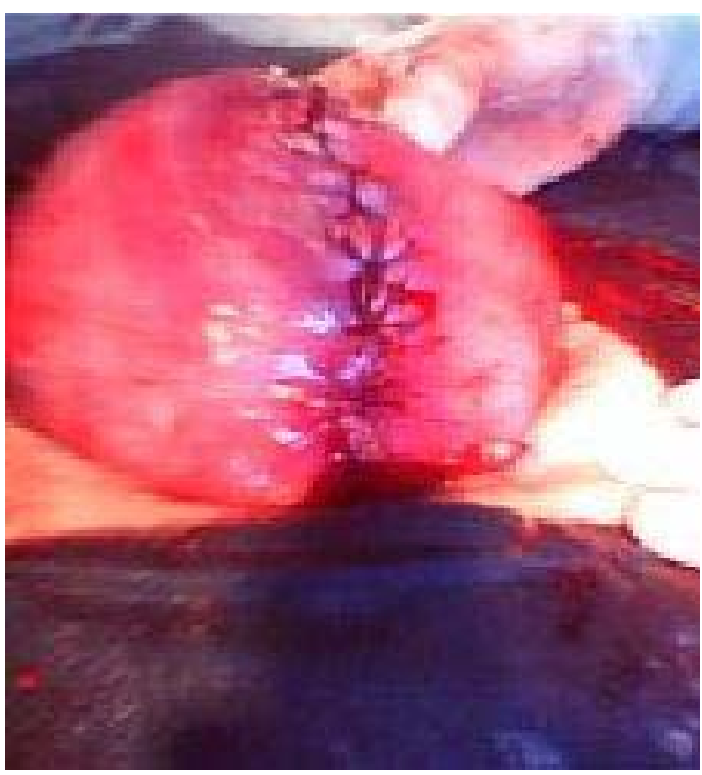

Fig 3. Repair of the uterus in classical caesarean. and 2 months of pregnancy, was referred from Biratnagar. She had been unable to conceive for a long time, this being her third pregnancy at a late age of 37 , ten years past marriage.

She was on regular antenatal supervision from 14 weeks of pregnancy. She had history of hypertension and diabetes running in the family. Both her father and sister were hypertensive and diabetic. Ultrasonography (USG) showed a single live pregnancy of 14 weeks with breech presentation with posterior low lying placenta free from the internal os with adequate liquor and a fibroid measuring $72.6 \times 48.4 \mathrm{~mm}$ in the body of the uterus posteriorly compressing the gestational sac. Around the same period, she had blood stained discharge per vagina and presuming to be threatened abortion, she was advised to take complete bed rest and weekly injection of HCG 5000 IU.

The uterine height also corresponded to her period of gestation at 18 and 26 weeks. She was duly immunized with 2 doses of tetanus toxoid and was on regular folic acid, iron and calcium. At 27 weeks she developed a single episode of rise in the blood pressure of 130/90 $\mathrm{mm} \mathrm{Hg}$ and was normotensive thereafter. Tablet isoxsuprine was added as she was experiencing pain abdomen on and off. Again at 36 weeks she was found to have blood pressure of $130 / 90 \mathrm{~mm} \mathrm{Hg}$. This time a decrease in uterine fundal height was noted corresponding to 32 weeks and a transverse lie. USG showed single live fetus of gestational age of 31 weeks with abdominal circumference (AC) measuring $260 \mathrm{~mm}$ corresponding to 30 weeks and 3 days. The estimated fetal weight was $1703.2 \mathrm{Gms}$. Placenta was posterior and in the upper uterine segment, and the liquor was very scanty. The myoma identified earlier appeared as ill defined hypoechoic space occupying lesion seen in the posterior part of the uterus, somewhat showing increase in the diameter of $72.6 \times 78 \times 75.6 \mathrm{~mm}$.

She was given 2 doses of dexamethasone and was referred to our institute for better neonatal care and management at 36 weeks of pregnancy with a severe IUGR fetus. On admission, blood pressure was 150/80 in the right and 160/100 in the left arm, pulse was 82 beats/min and edema was absent. Per abdominally, uterus was 26-28 weeks, relaxed, transverse lie, head in the right lumber region and fetal heart sound was 146 beats/min. There was no leaking or bleeding on vaginal examination, the os was closed and cervix posterior uneffaced.

All the PIH investigations except for the dip stick urinary protein, which was $2+$, were within normal limits. Repeat scan done on the same day showed single live pregnancy of 30-31 weeks with ?anal atresia, with severe oligohydramnious with AFI of $2.4 \mathrm{cms}$, 
transverse lie and posterior low lying placenta extending to the lower segment but not covering the internal os. The SD ratio was 3.2 , RI of 0.70 and PI of 1.06 , with a fibroid in the cervical part of the uterus about 8.3 X 6.2 $\mathrm{cms}$. The estimated fetal weight was $1563.1 \mathrm{gm}$.

Classical caesarean section was planned at 36 weeks for severe IUGR/PIH, severe oligohydramnious with transverse lie, cervical fibroid with posterior low lying placenta.

A vertical incision was given over the skin and the abdomen was opened in layers. After pushing the bladder down a vertical incision was given over the lower uterine segment which was extended vertically upwards to the upper uterine segment. Liquor was absent. As the baby was lying transversely in dorsosuperior position, it was extracted as breech, releasing two rounds of tight cord round the neck. The outcome was an alive male of $1.4 \mathrm{Kg}$ with 7/10 8/10 Apgar score. Baby was transferred to the neonatal care unit for observation and supportive management. Placenta was low lying almost up to the internal os which was manually removed. A soft cervical fibroid about $8 \times 8 \mathrm{~cm}$ more on the left side was visualized. Both tubes and the ovaries were adherent to the posterior fundal area of the uterus. There was a fibrinous deposit all over the posterior surface of the uterus. Pouch of Douglas (POD) was obliterated with the adhesions. Small haematoma formed over the fibrinous deposits at the posterior surface which was stitched. Uterus was closed in 2 layers. The blood pressure fell down to $60 \mathrm{~mm} \mathrm{Hg}$ (systolic) during the surgery because of intra operative blood loss of $1200 \mathrm{ml}$, so two units of blood and colloids were transfused. Corrugated rubber drain was kept on the right side of the uterus and the abdomen was closed in layers. At the end of surgery the urine output was $75 \mathrm{ml}$. The systolic blood pressure (BP) rose to 100 to $130 \mathrm{~mm} \mathrm{Hg}$ during closure of the parietal peritoneum and it kept on increasing postoperatively in the range of systolic130$200 \mathrm{~mm} \mathrm{Hg}$ and diastolic of $90-120 \mathrm{~mm} \mathrm{Hg}$.

Capsule Nifedipine $10 \mathrm{mg}$ was given stat and thereafter the blood pressure was maintained between 130-150 $\mathrm{mm} \mathrm{Hg}$ systolic and $90-100 \mathrm{mmHg}$ diastolic. The preoperative haemoglobin was $12.1 \mathrm{gm} \%$ and post operatively dropped to $10.4 \mathrm{gm} \%$ despite of two units of blood transfusion. On the $2^{\text {nd }}$ postoperative day (POD), she had slight distention of abdomen with minimal soakage of the wound. Dressing was done and the catheter was removed as her input and output were well maintained. She was put on tablet Nifedipine retard $10 \mathrm{mg}$ twice daily, Postoperatively on the $3^{\text {rd }}$ day she clinically looked pale for which she was again given two units of blood transfusion. As there was no soakage, drain was removed on the $4^{\text {th }}$ postoperative day and stitches were removed on the $7^{\text {th }}$ postoperative day. She waited for her baby till $19^{\text {th }}$ postoperative day when mother and baby were both discharged with the obstetric policy for elective CS in her next pregnancy.

\section{Comment}

CCS today is a time honored surgery and legendary to many of us hearing from senior obstetrician, telling of their experiences as CCS has been generally abandoned on account of associated per operative and postoperative hemorrhage, postoperative ileus and scar rupture during pregnancy before the on set of labor in the next pregnancy as early as 15 weeks, Coombe Women's Hospital giving the record of 62 such miseries. $^{4-8}$

CCS has been performed where lower uterine segment has not been well formed as in a preterm IUGR baby or transverse lie., ${ }^{2,7}$ A special circumstance that comes to mind is one that was performed through posterior uterine wall in the case of 180 degree dextrorotation of a gravid uterus with a large cervical fibroid where myomectomy was also done on the same seating. ${ }^{8}$ Our patient had much more indications that made us choose this procedure. Also the low vertical incision could be preferable. ${ }^{10}$

PPH is an important morbidity of classical caesarean section, as theoretically the upper segment does not contract or retract well. A study carried out in Canada by Lao $\mathrm{TT}^{2}$ et al has shown significant reduction in maternal haemoglobin following severe bleeding (estimated blood loss was $1000 \mathrm{ml}$ ) in CCS in comparison to the lower uterine caesaren section (LSCS) $(\mathrm{p}<0.05)$. Need for blood transfusion was higher, almost twice in CCS than in LSCS.

Our case fortunately, escaped all the complications cited in literature such as postpartum febrile infections like endoparametritis, abdominal wound infections, urinary tract and pulmonary infections, pelvic thrombophlebitis or even scar dehiscence. ${ }^{2-8}$ The real morbid one is anterior abdominal wall endometriosis from utero-abdominal sinus following CCS. ${ }^{5}$

Now days the trends of ' $J$ " or ' $U$ ' shaped incision is in practice where the vascularity to the uterus can be maintained and CCS to be reserved only during emergency thus inflicting a vertical lower midline incision in the uterus. ${ }^{10}$ 


\section{Conclusion}

Classical caesarean section can be practiced as favored option in very few selected cases anytime and anywhere in the virtue of the life of both the mother and her baby; such that the art of performing such a technique is retained for its application built on best faith in generations to come.

\section{References}

1. Bethune M, Permezel M. The relationship between gestational age and the incidence of classical caesarean section. Aust NZJ Obstet Gynaecol 1997 May; 37(2):153-5

2. Lao TT, Halpern SH, Crosby ET, Huh C. Uterine incision and maternal blood loss in preterm caesarean section. Arch Gynecol Obstet 1993; 252(3):113-7

3. Halperin ME, Moore DC, Harnah WJ. Classical verses low-segment transverse incision for preterm caesarean section: Maternal complications and outcome of subsequent pregnancies. Br J Obstet Gynaecol. 1998 Oct; 95(10): 990-6.
4. Blanco JD, Gibbs RS. Infections following classical caesarean section. Obstet Gynecol. 1980 Feb; 55(2):167-9

5. Aimakhu VE. Anterior abdominal wall endometriosis complicating an uteroabdominal sinus following classical caesarean section. Int Surg. 1975 Feb; 60(2):103-4

6. Endres LK, Barnhart K. Spontaneous second trimester uterine rupture after classical caesarean. Obstet Gynecol.2000 Nov; 96:806-8

7. Greene RA, Fitzpatrick C, Turner MJ. What are the maternal implications of a classical caesarean section? J Obstet Gynaecol 1998 Jul; 18(4); 345-7

8. Bolaji II, Rafla NM, Mylotte MJ, Classical caesarean section through posterior wall. Ir J Med Sci. 1992 Feb; 161(2): 46-7

9. Meinert J. Caesarean section in a dead woman. Gerburtshilfe Frauenheilhd 1982 Apr; 42(4): 310-2

10. St George L. Kauh KB. Low vertical uterine incision in Caesarean Section. Aust N Z J Obstet Gynecol. 1998 Feb; 27(1):10-3 